(C) The Authors 2018

\title{
Vitamin D receptor genotype influences risk of upper respiratory infection
}

\author{
David A. Jolliffe ${ }^{1 *}$, Claire L. Greiller ${ }^{1}$, Charles A. Mein ${ }^{2}$, Mimoza Hoti ${ }^{3}$, Eteri Bakhsoliani ${ }^{4}$, Aurica G. \\ Telcian $^{4}$, Angela Simpson ${ }^{5}$, Neil C. Barnes ${ }^{6}$, John A. Curtin ${ }^{5}$, Adnan Custovic ${ }^{7}$, Sebastian L. Johnston ${ }^{4,8}$, \\ Christopher J. Griffiths ${ }^{1,6}$, Robert T. Walton ${ }^{1}$ and Adrian R. Martineau ${ }^{1,6 *}$ \\ ${ }^{1}$ Centre for Primary Care and Public Health, Barts and The London School of Medicine and Dentistry, Queen Mary University \\ of London, London E1 $2 A B$, UK \\ ${ }^{2}$ The Genome Centre, Barts and The London School of Medicine and Dentistry, Queen Mary University of London, London E1 \\ $2 A T, U K$ \\ ${ }^{3}$ Department of Genetics, Evolution and Environment, University College London, London WC1E 6BT, UK \\ ${ }^{4}$ National Heart and Lung Institute, Imperial College London, London SW3 6LY, UK \\ ${ }^{5}$ Faculty of Biology, Division of Infection, Immunity and Respiratory Medicine, School of Biological Sciences, Manchester \\ Academic Health Science Centre, Medicine and Health University of Manchester, Manchester M13 9NT, UK \\ ${ }^{6}$ Asthma UK Centre for Applied Research, Barts and The London School of Medicine and Dentistry, Queen Mary University \\ of London, London E1 2AT, UK \\ ${ }^{7}$ Department of Paediatrics, Imperial College London, London W12 ONN, UK \\ ${ }^{8}$ MRC and Asthma UK Centre in Allergic Mechanisms in Asthma, Imperial College London, London W2 1NY, UK
}

(Submitted 9 January 2018 - Final revision received 26 May 2018 - Accepted 26 June 2018 - First published online 22 August 2018 )

\section{Abstract}

SNP in the vitamin D receptor $(V D R)$ gene is associated with risk of lower respiratory infections. The influence of genetic variation in the vitamin D pathway resulting in susceptibility to upper respiratory infections (URI) has not been investigated. We evaluated the influence of thirty-three SNP in eleven vitamin D pathway genes (DBP, DHCR7, RXRA, CYP2R1, CYP27B1, CYP24A1, CYP3A4, CYP27A1, LRP2, CUBN and $V D R$ ) resulting in URI risk in 725 adults in London, UK, using an additive model with adjustment for potential confounders and correction for multiple comparisons. Significant associations in this cohort were investigated in a validation cohort of 737 children in Manchester, UK. In all, three SNP in VDR (rs4334089, rs11568820 and rs7970314) and one SNP in CYP3A4 (rs2740574) were associated with risk of URI in the discovery cohort after adjusting for potential confounders and correcting for multiple comparisons (adjusted incidence rate ratio per additional minor allele $\left.\geq 1 \cdot 15, P_{\text {for trend }} \leq 0 \cdot 030\right)$. This association was replicated for rs 4334089 in the validation cohort $\left(P_{\text {for trend }}=0 \cdot 048\right)$ but not for rs11568820, rs7970314 or rs2740574. Carriage of the minor allele of the rs4334089 SNP in VDR was associated with increased susceptibility to URI in children and adult cohorts in the United Kingdom.

Key words: Vitamin D receptor: SNP: Upper respiratory infection

Upper respiratory infections (URI) (i.e. those affecting the respiratory tract above the level of the vocal cords) are most commonly of viral aetiology, although bacteria may also be responsible $^{(1)}$. URI commonly result in work absence and primary care consultations and impose a major economic burden on society ${ }^{(2)}$. They also cause a majority of acute exacerbations of asthma and chronic obstructive pulmonary disease $(\mathrm{COPD})^{(3)}$, which represent the main cause of morbidity and mortality in people with these conditions. Moreover, they are frequently inappropriately treated with antibiotics ${ }^{(4)}$, a practice which contributes to the emergence of antimicrobial resistance. In the absence of effective vaccines against the viruses that most commonly cause URI, identification of alternative preventive strategies is a research priority.

A growing body of evidence suggests that vitamin D supplementation may reduce the risk of URI in some clinical contexts. Vitamin D metabolites favourably modulate innate immune responses to respiratory viruses in vitro ${ }^{(5-9)}$ and numerous observational studies have reported independent inverse associations between circulating concentrations of 25-hydroxyvitamin D $(25(\mathrm{OH}) \mathrm{D}$, the major circulating vitamin $\mathrm{D}$ metabolite) and URI risk ${ }^{(10)}$. Meta-analyses of randomised controlled trials (RCT) of vitamin D supplementation for the prevention of acute respiratory infections and asthma

Abbreviations: 25(OH)D, 25-hydroxyvitamin D; aGMR, adjusted geometric mean ratios; aIRR, adjusted incidence rate ratio; CCL, C-C motif ligand; CXCL, C-X-C motif ligand; RSV, respiratory syncytial virus; RV, rhinovirus; URI, upper respiratory infection; VDR, vitamin D receptor.

*Corresponding authors: D. A. Jolliffe, fax +44 207882 2552, email d.a.jolliffe@qmul.ac.uk; A. R. Martineau, email a.martineau@qmul.ac.uk 
exacerbations (which are commonly precipitated by URI) have reported protective effects that are strongest in those with the lowest circulating $25(\mathrm{OH}) \mathrm{D}$ concentrations at baseline ${ }^{(11-13)}$. However, scepticism regarding protective effects of vitamin D against URI remains: this may in part reflect limitations inherent in the design of cross-sectional and case-control studies, where the possibility of reverse causality cannot be excluded ${ }^{(10)}$. Genetic studies represent an alternative approach to assessing whether the vitamin D pathway plays a causal role in protection against URI; a key strength is that associations seen cannot be attributed to reverse causality. In terms of mechanism, SNP in the gene encoding the vitamin $\mathrm{D}$ receptor $(V D R)$ may modify the protective efficacy of vitamin D-mediated host responses, for example, by influencing the structure of the VDR with consequences for transcription of vitamin D-regulated genes influencing immune function ${ }^{(14)}$. VDR polymorphisms have previously been reported to associate with susceptibility to acute lower respiratory infections (LRI) in diverse settings ${ }^{(15-18)}$; to date, however, the influence of SNP in VDR on susceptibility to URI has not been investigated. Moreover, no study has investigated whether polymorphisms in other genes in the vitamin D pathway that encode proteins are responsible for vitamin D metabolism, transport and signalling associated with URI risk. We, therefore, conducted an investigation to test the hypothesis that one or more of the thirty-three SNP in eleven vitamin D pathway genes (Fig. 1) influence the risk of URI and are associated with pathogen-stimulated concentrations of cytokines and chemokines. The association between genotype and risk of URI was investigated in a discovery cohort of 725 adults, with validation of positive hits in a cohort of 737 children. Where genetic associations were replicated in both cohorts, ex vivo host responses to viral stimuli were compared between genetically susceptible $v$. resistant individuals.

\section{Methods}

\section{Participants}

The discovery cohort comprised a total of 725 adults who participated in one of the three RCT of vitamin D supplementation to prevent acute respiratory infections conducted in London, UK, whose methods are described elsewhere ${ }^{(19-21)}$. All studies were approved by East London and The City Research Ethics Committee 1 (Refs. 09/H0703/67, 09/H0703/76 and 09/ H0703/112), and written informed consent was obtained from all participants before enrolment. The validation cohort comprised 737 children who were enrolled in the Manchester Asthma and Allergy Study (MAAS), a population-based birth cohort study whose methods are described elsewhere ${ }^{(22)}$. Children were recruited prenatally, and were born between 20 April 1995 and 13 April 2000. The study was approved by the Research Ethics Committee Greater Manchester East, NRES Committee (Ref. no. 14/NW/1309) and parents gave written informed consent for their children to participate.

\section{Procedures}

Clinical data collection. At enrolment, participants in the discovery cohort completed questionnaires detailing lifestyle and demographic factors relating to risk of URI including smoking history, influenza vaccination history, socio-economic position, age, sex and racial/ethnic origin. A baseline blood sample was collected from all participants for DNA extraction and isolation of serum for determination of $25(\mathrm{OH}) \mathrm{D}$ concentration. For a representative sub-set of 185 participants, a sample of whole blood was also incubated with a panel of Toll-like receptor (TLR) ligands and respiratory viruses for $24 \mathrm{~h}$, as described in the forthcoming paragraphs. Participants were invited back 2 weeks after their baseline visit to be randomised to receive intervention

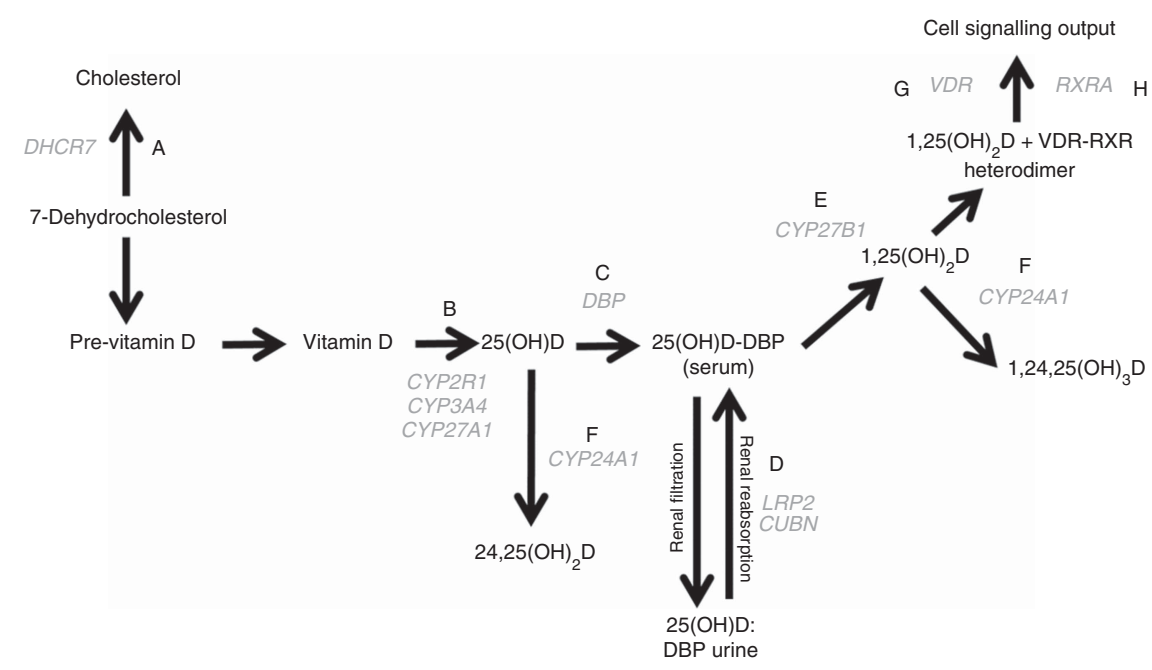

Fig. 1. The vitamin $D$ pathway. $D H C R 7(A)$ encodes the 7-dehydrocholesterol reductase enzyme, which catalyses the conversion of 7-dehydrocholesterol to cholesterol; CYP2R1, CYP3A4, and CYP27A1 (B) encode 25-hydroxylating cytochrome P450 enzymes; the vitamin D binding protein gene (DBP (C)) encodes the principal vitamin D transport protein; $L R P 2$ and $C U B N(D)$ encode the proteins megalin and cubilin, respectively, involved in renal re-absorption of 25-hydroxyvitamin $D$ $(25(\mathrm{OH}) \mathrm{D})$ via receptor-mediated endocytosis; CYP27B1 (E) encodes the cytochrome P450 enzyme which 1- $\alpha$-hydroxylates 25(OH)D to form 1,25-dihydroxyvitamin D $\left(1,25(\mathrm{OH})_{2} \mathrm{D}\right) ; C Y P 24 A 1(\mathrm{~F})$ encodes the cytochrome $\mathrm{P} 450$ enzyme responsible for 24-hydroxylating vitamin $\mathrm{D}$ metabolites including $25(\mathrm{OH}) \mathrm{D}$ and $1,25(\mathrm{OH})_{2} \mathrm{D} ; \mathrm{VDR}$ (G) encodes the vitamin $\mathrm{D}$ receptor, which is ligated by $1,25(\mathrm{OH})_{2} \mathrm{D}$ and forms a heterodimer with the gene product of $R X R A(\mathrm{H})-$ the retinoid $\mathrm{X}$ receptor - to mediate the biological actions of vitamin D. Gene symbols are shown in grey. 
or control regimens as summarised in online Supplementary Table S1 over a 1-year period, during which they completed a daily diary of URI symptoms. Symptom scores were used to define incident URI, as previously described, and validated in a subset of participants in the Vitamin D supplementation in prevention of influenza (ViDiFlu) trial ${ }^{(21)}$ using PCR detection of eleven respiratory viruses obtained by nasopharyngeal swabs.

MAAS participants attended follow-up visits at the ages of 1, 3, 5, 8 and 11 years. At each visit, a validated questionnaire was used to collect information on incidence of URI diagnosed by a primary care physician. We extracted all data from primary care medical records, including URI, emergency department admissions and hospitalisations and prescriptions of asthma medications and oral corticosteroids $^{(23)}$. Self-reported episodes were validated against primary care records. Blood samples were collected at age 11 years for peripheral blood mononuclear cell (PBMC) isolation and cryopreservation pending ex vivo stimulation ${ }^{(24)}$

SNP selection in the discovery cohort. A literature search of the PubMed database was performed to identify SNP previously shown to associate with serum $25(\mathrm{OH}) \mathrm{D}$ concentration and/or risk of non-skeletal disease ${ }^{(25)}$. A total of fifty-four such SNP in eleven genes in the vitamin D pathway were identified; their function is illustrated in Fig. 1. TagSNP were selected based on linkage disequilibrium information from the HapMap database (release \#27: phases 1, 2 and 3 - merged genotypes and frequencies); 'Utah residents with Northern and Western European ancestry from the Centre d'Etude du Polymorphisme Humain (CEPH) collection (CEU)' dataset, represented the discovery cohort, of whom $83 \%$ of participants were of White European ethnic/racial origin. Using Bioinformatics' Haploview program (version 3.3), selecting the 'pairwise tagging only' option, setting the $r^{2}$ threshold to $>0.8$ and accepting a minimum genotype completeness of $75 \%$ and a minor allele frequency threshold of 0.04 , tagging reduced the number of alleles to be genotyped from fifty-four to thirty-seven SNP. Subsequent to closure of the HapMap database, tagging was re-checked using the 1000 genomes reference set under the same parameters, which highlighted two additional pairwise associations in the SNP panel. Thus, rs11568820 was chosen to capture rs7976091 $\left(r^{2} 1 \cdot 0\right)$, and rs1544410 was chosen to capture rs731236 $\left(r^{2} 1 \cdot 0\right)$, reducing the panel to thirty-five SNP.

DNA extraction and genotyping. For the discovery cohort, genotyping was conducted at the Genome Centre at Queen Mary University of London. DNA was extracted from whole blood using a salting-out method previously described ${ }^{(26)}$ on the Biomek FX robot (Beckman Coulter), quantified using the Nanodrop spectrophotometer (Thermo Scientific) and normalised to $5 \mathrm{ng} /$ $\mu \mathrm{l}$. In all, $10 \mathrm{ng}$ DNA were used as template for $2 \mu \mathrm{T} \mathrm{TaqMan}$ assays (Applied Biosystems) performed on the ABI $7900 \mathrm{HT}$ platform in 384-well format and analysed with Autocaller software. Typing for two SNP failed (rs6127118, CYP24A1 and rs11574010, VDR), reducing the panel for analysis to thirty-three SNP.

For the validation cohort, genomic DNA was extracted from blood using the phenol-chloroform method and genotyped on an Illumina 610 quad array (Illumina) and quality controlled as described previously ${ }^{(27)}$. Genotypes were subsequently prephased (SHAPEIT version 2.5.1) and imputed (IMPUTE2 version 2.3.2) with the 1000 genomes haplotypes - phase 3 integrated variant set reference genotypes. In all, one SNP was genotyped (rs4334089) and three SNP were imputed (rs11568820, rs7970314 and rs2740574); their info scores ${ }^{(28)}$ were $0.99,0.99$ and 0.97, respectively.

Whole blood assays. Stocks of rhinovirus (RV)-1B, RV-16 and respiratory syncytial virus (RSV) were prepared as previously described $^{(9)}$. Samples of whole blood from a sub-set of participants in the discovery cohort were stimulated with the following TLR ligands and pathogens in sterile ninety-six-well polystyrene microplates (Corning Incorporated): polyinosinic: polycytidylic acid (poly I:C; InvivoGen; working stock concentration $1 \mathrm{mg} / \mathrm{ml}$ ), resiquimod (R848; InvivoGen; working stock concentration $10 \mu \mathrm{g} / \mathrm{ml}$ ), RV-1B (working stock titre $8.8 \times 10^{7}$ tissue culture infective dose $\left.50 \%\left(\operatorname{TCID}_{50}\right) / \mathrm{ml}\right), \mathrm{RV}-16$ (working stock titre $9.8 \times 10^{7} \mathrm{TCID}_{50} / \mathrm{ml}$ ) and RSV (working stock titre $4 \times 10^{6}$ plaque-forming units $/ \mathrm{ml}$ ). In all, $180 \mu \mathrm{l}$ of whole blood was incubated with $20 \mu \mathrm{l}$ of a solution/suspension of the working stock of stimulant or vehicle (PBS) in a humidified incubator at $37^{\circ} \mathrm{C}$ and $5 \% \mathrm{CO}_{2}$ for $24 \mathrm{~h}$. Supernatants were then aspirated and stored at $-80^{\circ} \mathrm{C}$ pending analysis by multiplex ELISA (Human Cytokine Magnetic 30-Plex Panel; Invitrogen), following manufacturer's instructions. Concentrations of the following inflammatory mediators were determined: IL-1 $\beta$, IL-2, IL-4, IL-5, IL-6, IL-7, IL-8 (C-X-C motif ligand (CXCL)8), IL-10, IL-12, IL-13, IL-15, IL-17, IL-1RA, IL-2R, interferon (IFN)- $\alpha$, IFN- $\gamma$, TNF, C-C motif ligand (CCL)-2 (monocyte chemoattractant protein-1), CCL3 (macrophage inflammatory protein (MIP)- $1 \alpha$ ), CCL4 (MIP-1 $\beta$ ), CCL5 (RANTES), CCL11 (eotaxin-1), CXCL9 (monokine induced by IFN- $\gamma$; MIG), CXCL10 (inducible protein (IP)-10), epidermal growth factor (EGF), fibroblast growth factor (FGF)-basic, hepatocyte growth factor (HGF), vascular endothelial growth factor (VEGF), granulocyte colony-stimulating factor (G-CSF) and granulocyte-macrophage colony-stimulating factor (GM-CSF).

Peripheral blood mononuclear cell assays. Methods of the PBMC assays performed in the validation cohort are described in detail elsewhere ${ }^{(24)}$. Briefly, cryopreserved PBMC were thawed and distributed in ninety-six-well plates $\left(2 \times 10^{5}\right.$ cells per well) before stimulation with respiratory viruses (RV1B, RV16 and RSV, all at a multiplicity of infection (ratio of infectious agents to infection targets) of 1$)$, resiquimod ( $1 \mu \mathrm{m}$ final concentration) or medium. Supernatants were harvested $24 \mathrm{~h}$ after stimulation and concentrations of IFN- $\alpha$, IFN- $\gamma$, CXCL10, IL-1 $\beta$, IL-6 and TNF were measured with the Meso Scale Discovery Multi-array.

Measurement of vitamin D status. Serum concentrations of $25(\mathrm{OH}) \mathrm{D}_{2}$ and $25(\mathrm{OH}) \mathrm{D}_{3}$ were determined by isotope-dilution liquid chromatography-tandem MS in the Department of Clinical Biochemistry at Homerton Hospital, and summed to give total serum 25(OH)D concentration. The limit of detection for $25(\mathrm{OH}) \mathrm{D}_{2}$ and $25(\mathrm{OH}) \mathrm{D}_{3}$ was $10 \mathrm{nmol} / \mathrm{l}$; mean percentage bias 
was $-0 \cdot 70$ (sD $7 \cdot 35$ ); $95 \%$ limits of agreement were from $-15 \cdot 1$ to 13.7. Undetectable results were treated as zero values. This laboratory participates in the international vitamin D external quality assurance scheme (www.deqas.org/).

Statistical analyses. Statistical analyses were conducted using STATA version 12 and SNPTEST version 2.5.1. The influence of genotype on rate of URI or proportion with one or more URI was analysed with negative binomial regression and the Cochran-Armitage test, respectively. All SNP were analysed using the per-allele method, that is, under an additive model. Regression models for the discovery cohort were adjusted for the following potential confounders of the relationship between genotype and URI risk: age, sex, racial/ethnic origin, influenza vaccination history, smoking history, baseline vitamin D status, allocation to vitamin $\mathrm{D} v$. placebo and presence of respiratory morbidity (asthma $v$. COPD $v$. none). Covariates were classified as categorical variables, with the exception of age and baseline vitamin D status, which were fitted as continuous variables. In the validation cohort, participants whose parents identified their ethnic origin as being other than 'White European' (3\% of the study population) were excluded from genetic analyses. Ethnicity was controlled for in the statistical analysis of the discovery cohort and a sensitivity analysis excluding data from participants who identified their ethnic origin as being other than 'White European' (15\% of the study population) was performed for significant SNP-URI risk associations. An additional sensitivity analysis removing participants in the intervention arm was performed on significant SNP-URI risk associations in the discovery cohort to account for variation in serum response to vitamin D supplementation. Supernatant concentrations of inflammatory mediators were transformed to their natural logarithms before regression analysis. Regression coefficients were then exponentiated to give adjusted geometric mean ratios (aGMR) with associated $95 \% \mathrm{CI}$ and $P$ values for trend. The Benjamini-Hochberg procedure for multiple testing correction was applied to analyse URI rate and immunological data to control the false discovery rate (FDR) at $10 \%$.

\section{Results}

\section{Study populations}

Characteristics of the 725 participants in the discovery cohort are presented in Table 1 . They ranged from 16 to 94 years of age, with a mean of 59.7 (sD 15.0) years, and $54 \%$ were female. In all, $67 \%$ of participants had respiratory comorbidity $(34 \%$ asthma; $33 \%$ COPD). The majority of participants classified their racial/ethnic origin as 'White European' (85\%); $9 \%$ classified their racial/ethnic origin as Black/Black British; $4 \%$ as Asian/Asian British and $2 \%$ as mixed. At baseline, the mean serum 25(OH)D concentration was $46 \cdot 3$ (sD 24.7) nmol/l. Average duration of participation was 0.93 years, and participants had a total of 677 participant-years of follow-up. Immunological data were available for 180 participants in the discovery cohort; characteristics of this sub-set of participants were similar to those of participants who did not contribute immunological data (online Supplementary Table S2). Detailed
Table 1. Baseline participant characteristics, discovery cohort (Numbers and percentages; mean values and standard deviations)

\begin{tabular}{|c|c|c|}
\hline & \multicolumn{2}{|c|}{ Discovery cohort ( $n$ 725) } \\
\hline & $n$ & $\%$ \\
\hline \multicolumn{3}{|l|}{ Sex } \\
\hline Female & 394 & $54 \cdot 3$ \\
\hline Male & 331 & $45 \cdot 7$ \\
\hline \multicolumn{3}{|l|}{ Age (years) } \\
\hline Mean & \multicolumn{2}{|c|}{$59 \cdot 7$} \\
\hline SD & \multicolumn{2}{|c|}{$15 \cdot 0$} \\
\hline \multicolumn{3}{|l|}{ BMI $\left(\mathrm{kg} / \mathrm{m}^{2}\right)$} \\
\hline Mean & \multicolumn{2}{|c|}{$28 \cdot 2$} \\
\hline SD & \multicolumn{2}{|c|}{$6 \cdot 2$} \\
\hline \multicolumn{3}{|l|}{ Ethnicity* } \\
\hline White & 613 & $84 \cdot 8$ \\
\hline Asian/Asian British & 31 & $4 \cdot 3$ \\
\hline Black/Black British & 62 & $8 \cdot 6$ \\
\hline Other & 17 & $2 \cdot 3$ \\
\hline \multicolumn{3}{|l|}{ Socio-economic position† } \\
\hline $\begin{array}{l}\text { Managerial/administrative/ } \\
\text { professional/intermediate professions }\end{array}$ & 408 & $56 \cdot 3$ \\
\hline $\begin{array}{l}\text { Small employers/own account } \\
\text { workers, supervisory/technical } \\
\text { occupations, semi-routine/routine } \\
\text { occupations }\end{array}$ & 293 & $40 \cdot 4$ \\
\hline Student & 6 & 0.9 \\
\hline Unemployed & 9 & 1.4 \\
\hline \multicolumn{3}{|l|}{ Quarter of blood draw } \\
\hline Q1 (January-March) & 229 & 31.6 \\
\hline Q2 (April-June) & 180 & $24 \cdot 8$ \\
\hline Q3 (July-September) & 138 & $19 \cdot 0$ \\
\hline Q4 (October-December) & 178 & $24 \cdot 6$ \\
\hline \multicolumn{3}{|l|}{ Smoking status } \\
\hline Non-current & 568 & $78 \cdot 3$ \\
\hline Current & 157 & $21 \cdot 7$ \\
\hline \multicolumn{3}{|l|}{ Alcohol intake (units/week) $\ddagger$} \\
\hline Mean & \multicolumn{2}{|c|}{$9 \cdot 2$} \\
\hline SD & \multicolumn{2}{|c|}{14.9} \\
\hline \multicolumn{3}{|l|}{ Influenza vaccination } \\
\hline Yes & 592 & $81 \cdot 7$ \\
\hline No & 133 & $18 \cdot 3$ \\
\hline \multicolumn{3}{|l|}{ Respiratory comorbidity } \\
\hline Asthma & 248 & $34 \cdot 2$ \\
\hline Chronic obstructive pulmonary disease & 239 & $33 \cdot 0$ \\
\hline None & 238 & $32 \cdot 8$ \\
\hline \multicolumn{3}{|l|}{ Baseline serum 25(OH)D (nmol/l) } \\
\hline$<25$ & 145 & $20 \cdot 0$ \\
\hline $25-49 \cdot 9$ & 297 & $41 \cdot 0$ \\
\hline $50-74.9$ & 188 & $25 \cdot 9$ \\
\hline$\geq 75$ & 95 & $13 \cdot 1$ \\
\hline \multicolumn{3}{|l|}{ Baseline serum 25(OH)D (nmol/l) } \\
\hline Mean & & \\
\hline SD & & \\
\hline
\end{tabular}

25(OH)D, 25-hydroxyvitamin D.

* Ethnicity not reported in $n$ 3. Other ethnicities: $n 7$ White and Black Caribbean, $n 2$ White and Asian, $n 2$ White and Black African, $n 1$ Irish - Sri Lankan, $n 1$ Spanish Filipino, $n 1$ Asian Caribbean, $n 1$ Mauritian, $n 2$ preferred not to disclose. † Socio-economic position not reported in $n 9$.

$\ddagger$ Alcohol consumption not reported in $n 13$. One alcohol unit $=8 \mathrm{~g}$ pure alcohol.

characteristics of the replication population are presented elsewhere $^{(24)}$ and summarised in online Supplementary Table S3. Briefly, 737 participants had data on URI and genotyping data. Average duration of participation was 9.97 years, and participants had a total of 7350 participant-years of follow-up. PBMC stimulation data and genotyping data were available for 228 children. 


\section{Genetic determinants of upper respiratory infections risk}

Results of statistical analyses to determine the influence of genotype on risk of URI in the discovery cohort are presented in Table 2. After adjusting for potential confounders and correcting for multiple comparisons testing, carriage of minor alleles for three SNP in VDR and one SNP in CYP3A4 were found to associate with increased URI risk. Adjusted incidence rate ratios (aIRR) per additional minor allele, generated by additive models, are as follows: for rs4334089 in $V D R$, aIRR $=1 \cdot 15,95 \%$ CI $1 \cdot 01,1 \cdot 31$, $P=0.03$; for $\mathrm{rs} 11568820$ in $V D R$, aIRR $=1.23,95 \%$ CI $1.07,1.40$, $P=0 \cdot 002$; for rs 7970314 , aIRR $=1 \cdot 17,95 \%$ CI $1 \cdot 02,1 \cdot 34, P=0 \cdot 018$; and for rs2740574 in CYP3A4, aIRR $=1 \cdot 27,95 \%$ CI $1.03,1.56$, $P=0.025$. Results of two sensitivity analyses to determine the influence of rs4334089, rs11568820, rs7970314 and rs2740574 on risk of URI, restricted to participants of white European ethnicity and the placebo arm, are presented in online Supplementary Tables S4 and S5, respectively. All SNP-URI associations remained significant $(P \leq 0.048)$ for both sensitivity analyses. We also performed an exploratory interaction analysis to determine whether the influence of rs4334089 genotype on risk of URI in discovery cohort participants was modified by baseline vitamin D status ( 25 $(\mathrm{OH}) \mathrm{D}<25 v$. $\geq 25 \mathrm{nmol} / \mathrm{l})$. We found no evidence of effect modification ( $P$ value for interaction $=0.38$ ).

We then proceeded to investigate whether these SNP also associated with susceptibility to URI in the validation cohort of children. Results of these analyses are presented in Table 3. The association between carriage of the minor allele for rs 4334089 and increased susceptibility to URI originally observed in the discovery cohort was replicated in the validation cohort: the proportion of children experiencing at least one physiciandiagnosed URI with AA $v$. AG $v$. GG genotypes was $6 / 56$ $(10.7 \%) \quad v .23 / 278(8.3 \%) \quad v .21 / 403 \quad(5 \cdot 2 \%)$, respectively ( $P_{\text {for trend }}=0 \cdot 048$ ). No associations between imputed genotypes for rs11568820, rs7970314 or rs2740574 and URI susceptibility were seen in the validation cohort.

\section{Genetic variation in ex vivo virus-stimulated inflammatory} profiles

Having replicated the association between rs4334089 genotype and susceptibility to URI in separate cohorts of children and adults, we proceeded to investigate whether genetic variation at this locus was also associated with differences in host response to ex vivo viral stimuli in both discovery and validation cohorts. In the discovery cohort, concentrations of thirty inflammatory mediators in supernatants of virus-stimulated whole blood were compared between three groups of participants defined by their rs4334089 genotype ( $G G v$. AG $v$. AA). After correction for potential confounders, statistically significant differences in supernatant concentrations of four inflammatory mediators were found (Fig. 2). Carriage of the minor allele of rs4334089previously shown to associate with increased susceptibility to URI - associated with lower supernatant concentrations of IL-2R (RSV stimulation: aGMR 0.92, 95\% CI 0.84, 0.99, $P_{\text {for trend }}=0.047$; poly I:C stimulation: aGMR 0.89; $95 \%$ CI 0.79 , 0.99; $P=0 \cdot 041$ ), CCL5 (RV1-B stimulation: aGMR 0.66, $95 \% \mathrm{CI}$ $\left.0 \cdot 46,0.94, P_{\text {for trend }}=0.023\right)$, CXCL9 (RV-16 stimulation: aGMR
0.84, 95\% CI 0.71, 1.00; $\left.P_{\text {for trend }}=0.054\right)$ and IL-1RA (RSV stimulation: aGMR 0.91, 95\% CI 0.83, 0.99; $\left.P_{\text {for trend }}=0.042\right)$. rs4334089 genotype also influenced host response in the MAAS validation cohort of children, where carriage of the minor allele was associated with lower supernatant concentration of resiquimod-stimulated CXCL10 (GMR 0.78, 95\% CI 0.64, 0.96; $P_{\text {for trend }}=0.017$; Fig. 2). However, none of these differences remained statistically significant after correction for multiple comparisons testing, using the Benjamini and Hochberg method with a FDR of $10 \%$.

\section{Discussion}

To our knowledge, this is the first study to investigate the influence of genetic variation in the vitamin D pathway on URI risk. We report that carriage of minor alleles for three SNP in VDR (rs4334089, rs11568820 and rs7970314) and one SNP in CYP3A4 (rs2740574) associated with increased risk of URI in a cohort of adults after correction for potential confounders and multiple comparison testing; these associations were robust to sensitivity analysis restricted to those who classified their ethnic origin as being 'White European'. We achieved partial replication of these findings by additionally demonstrating an association between carriage of the minor allele for rs4334089 and increased susceptibility to URI in a validation cohort of children. Since the function of $V D R$ is specific to vitamin D signalling, our results complement the growing body of evidence from in vitro studies, observational epidemiology and RCT suggesting that vitamin $\mathrm{D}$ plays a role in defence against viral respiratory infections.

Our study adds to the body of literature reporting associations between VDR polymorphisms and susceptibility to diverse infectious diseases, including LRI $^{(15-18,29)}$. The mechanisms underlying such associations have only been elucidated in some cases: for example, the mutant allele of the FokI polymorphism encodes a shorter VDR protein that results in higher $\mathrm{NF}-\kappa \mathrm{B}-$ driven transcription, enhanced expression of IL-12 and more vigorous lymphocyte proliferation in response to phytohaemagglutinin ${ }^{(14)}$. In the absence of evidence that the rs4334089 polymorphism has similar functional consequences, we presume that the association demonstrated here arises as a result of this SNP being in linkage disequilibrium with a functional variant elsewhere in the $V D R$ gene that has yet to be identified. Other studies have reported associations between the rs4334089 genotype and susceptibility to Parkinson's and Alzheimer's diseases ${ }^{(30)}$, as well as responsiveness to vitamin D supplementation in patients with tuberculosis ${ }^{(31)}$.

Our immunological findings also have biological plausibility: since vitamin D modulates TLR expression via VDR signalling ${ }^{(32-34)}$, it follows that genetic variation at the VDR has potential to influence TLR ligand-stimulated responses. With regard to specific cytokines and chemokines, IL-1RA plays a key role in resolution of RV infection ${ }^{(35,36)}$, while CCL5 has been reported to inhibit RSV infection in a human respiratory epithelial cell line ${ }^{(37)}$ and to promote RSV clearance in mice ${ }^{(38)}$. CCL5, CXCL9 and CXCL10 recruit T lymphocytes in the context of respiratory virus infection ${ }^{(37-40)}$. Reduced production of these 
Table 2. Genetic determinants of upper respiratory infection risk, discovery cohort (Numbers and $95 \%$ confidence intervals)

\begin{tabular}{|c|c|c|c|c|c|c|c|c|}
\hline Gene & SNP & Genotype & $n$ & $\begin{array}{c}\text { No. of URI per } \\
\text { person-year of follow-up }\end{array}$ & Rate & $\begin{array}{c}\text { Adjusted incidence } \\
\text { rate ratio per additional } \\
\text { minor allele* }\end{array}$ & $95 \% \mathrm{Cl}$ & $P_{\text {for trend }}$ \\
\hline \multirow[t]{3}{*}{ CUBN } & rs3740165 & TT & 651 & $1033 / 604 \cdot 3$ & $1 \cdot 71$ & 0.85 & $0 \cdot 61,1 \cdot 18$ & 0.34 \\
\hline & & $\mathrm{TC}$ & 54 & $77 / 50 \cdot 1$ & 1.54 & & & \\
\hline & & $\mathrm{CC}$ & $2 \dagger$ & $0 / 2 \cdot 1$ & 0.0 & & & \\
\hline \multirow[t]{12}{*}{ CYP24A1 } & rs2762939 & $\mathrm{GG}$ & 372 & $590 / 345 \cdot 6$ & $1 \cdot 71$ & 1.01 & $0.88,1.17$ & 0.85 \\
\hline & & CG & 279 & $462 / 262 \cdot 2$ & 1.76 & & & \\
\hline & & $\mathrm{CC}$ & 60 & $82 / 52 \cdot 1$ & 1.57 & & & \\
\hline & rs2248137 & $\mathrm{CC}$ & 245 & $377 / 233.5$ & 1.61 & 1.02 & $0.89,1.15$ & 0.82 \\
\hline & & CG & 335 & $569 / 306 \cdot 0$ & 1.86 & & & \\
\hline & & $\mathrm{GG}$ & 133 & $181 / 122 \cdot 0$ & 1.48 & & & \\
\hline & rs2762934 & $\mathrm{GG}$ & 498 & $792 / 461 \cdot 7$ & $1 \cdot 72$ & 0.97 & $0.82,1.14$ & 0.70 \\
\hline & & $A G$ & 191 & $307 / 179 \cdot 0$ & $1 \cdot 72$ & & & \\
\hline & & $\mathrm{AA}$ & 22 & 22/18.3 & $1 \cdot 20$ & & & \\
\hline & rs6013897 & TT & 445 & $707 / 415 \cdot 7$ & $1 \cdot 70$ & 1.05 & $0.90,1.21$ & 0.55 \\
\hline & & AT & 228 & $342 / 207 \cdot 4$ & 1.65 & & & \\
\hline & & AA & 37 & $71 / 34 \cdot 0$ & 2.09 & & & \\
\hline \multirow[t]{3}{*}{ CYP27A1 } & rs17470271 & AA & 279 & $416 / 261.9$ & 1.59 & 1.08 & $0.95,1.22$ & 0.25 \\
\hline & & AT & 323 & $551 / 293 \cdot 8$ & 1.88 & & & \\
\hline & & TT & 115 & $180 / 109 \cdot 2$ & 1.65 & & & \\
\hline \multirow[t]{6}{*}{ CYP27B1 } & rs4646537 & TT & 645 & $1019 / 599 \cdot 8$ & $1 \cdot 70$ & 1.02 & $0.74,1.39$ & 0.91 \\
\hline & & $\mathrm{GT}$ & 63 & $97 / 56 \cdot 6$ & $1 \cdot 71$ & & & \\
\hline & & $\mathrm{GG}$ & 0† & $0 / 0$ & 0.0 & & & \\
\hline & rs4646536 & $\mathrm{AA}$ & 324 & $518 / 303 \cdot 8$ & $1 \cdot 71$ & 0.97 & $0.85,1.10$ & 0.61 \\
\hline & & $A G$ & 303 & $492 / 276.4$ & $1 \cdot 78$ & & & \\
\hline & & $\mathrm{GG}$ & 81 & $114 / 75 \cdot 7$ & 1.51 & & & \\
\hline \multirow[t]{9}{*}{ CYP2R1 } & rs10500804 & TT & 269 & $405 / 248 \cdot 7$ & 1.63 & 1.08 & $0.95,1.22$ & $0 \cdot 26$ \\
\hline & & GT & 340 & $561 / 313 \cdot 9$ & $1 \cdot 79$ & & & \\
\hline & & $\mathrm{GG}$ & 110 & $176 / 103 \cdot 8$ & $1 \cdot 70$ & & & \\
\hline & rs2060793 & GG & 249 & $427 / 233 \cdot 1$ & 1.83 & 0.92 & $0.81,1.04$ & 0.18 \\
\hline & & $A G$ & 340 & $523 / 311 \cdot 0$ & 1.68 & & & \\
\hline & & AA & 120 & $180 / 112 \cdot 4$ & 1.60 & & & \\
\hline & rs10766197 & $\mathrm{GG}$ & 233 & $352 / 217 \cdot 0$ & 1.62 & 1.07 & $0.94,1.22$ & 0.32 \\
\hline & & $A G$ & 342 & $561 / 313 \cdot 6$ & $1 \cdot 79$ & & & \\
\hline & & AA & 118 & $187 / 110 \cdot 7$ & 1.69 & & & \\
\hline \multirow[t]{3}{*}{ СYРЗА4 } & rs2740574 & AA & 608 & $940 / 567 \cdot 7$ & 1.66 & $1 \cdot 27$ & $1.03,1.56$ & $0.025 \ddagger$ \\
\hline & & $A G$ & 77 & $143 / 69.5$ & 2.06 & & & \\
\hline & & GG & 33 & $60 / 29 \cdot 4$ & 2.04 & & & \\
\hline \multirow[t]{18}{*}{$D B P$} & rs7041 & $\mathrm{CC}$ & 192 & $294 / 179 \cdot 3$ & 1.64 & $1 \cdot 13$ & $1.00,1.29$ & 0.060 \\
\hline & & $A C$ & 343 & $535 / 319 \cdot 4$ & 1.68 & & & \\
\hline & & AA & 173 & $287 / 157 \cdot 6$ & 1.82 & & & \\
\hline & rs4588 & $\mathrm{GG}$ & 382 & $587 / 356 \cdot 5$ & 1.65 & $1 \cdot 11$ & $0.96,1.29$ & 0.16 \\
\hline & & GT & 290 & $483 / 269 \cdot 3$ & $1 \cdot 79$ & & & \\
\hline & & TT & 48 & $70 / 42 \cdot 1$ & 1.66 & & & \\
\hline & rs12512631 & TT & 305 & $459 / 284 \cdot 0$ & 1.62 & 1.00 & $0.88,1.14$ & 0.97 \\
\hline & & $\mathrm{CT}$ & 331 & $526 / 303 \cdot 1$ & 1.74 & & & \\
\hline & & $\mathrm{CC}$ & 80 & $114 / 78 \cdot 2$ & 1.46 & & & \\
\hline & rs2070741 & TT & 603 & $944 / 561 \cdot 1$ & 1.68 & 0.93 & $0.73,1.19$ & 0.56 \\
\hline & & TG & 102 & $171 / 93 \cdot 4$ & 1.83 & & & \\
\hline & & $\mathrm{GG}$ & $0 \dagger$ & $0 / 0$ & 0.0 & & & \\
\hline & rs2298849 & AA & 445 & $727 / 420 \cdot 1$ & 1.73 & 0.99 & $0.86,1.15$ & 0.93 \\
\hline & & $A G$ & 231 & $350 / 205.9$ & $1 \cdot 70$ & & & \\
\hline & & GG & 40 & $66 / 38 \cdot 1$ & 1.73 & & & \\
\hline & rs16846876 & $\mathrm{AA}$ & 340 & $546 / 317 \cdot 7$ & 1.72 & 1.00 & $0.86,1.16$ & 0.98 \\
\hline & & AT & 323 & $520 / 297 \cdot 7$ & 1.75 & & & \\
\hline & & TT & 52 & $63 / 47 \cdot 0$ & $1 \cdot 34$ & & & \\
\hline \multirow[t]{6}{*}{ DHCR7 } & rs3829251 & GG & 532 & $827 / 492 \cdot 1$ & 1.68 & 1.04 & $0.87,1.24$ & 0.66 \\
\hline & & $A G$ & 162 & $273 / 151 \cdot 8$ & 1.80 & & & \\
\hline & & $\mathrm{AA}$ & 16 & $21 / 14 \cdot 0$ & 1.50 & & & \\
\hline & rs12785878 & TT & 394 & $618 / 364 \cdot 1$ & $1 \cdot 70$ & $1 \cdot 10$ & $0.95,1.27$ & 0.22 \\
\hline & & GT & 241 & $372 / 227 \cdot 2$ & 1.64 & & & \\
\hline & & GG & 83 & $153 / 75 \cdot 3$ & 2.03 & & & \\
\hline \multirow{3}{*}{$L R P 2$} & rs3755166 & GG & 263 & $431 / 242 \cdot 0$ & $1 \cdot 78$ & 0.90 & $0.80,1.03$ & 0.12 \\
\hline & & $A G$ & 346 & $559 / 322 \cdot 8$ & 1.73 & & & \\
\hline & & AA & 112 & $156 / 103 \cdot 7$ & 1.50 & & & \\
\hline \multirow[t]{3}{*}{$R \times R A$} & rs7861779 & GG & 464 & $763 / 431.5$ & 1.77 & 0.95 & $0.81,1.12$ & 0.60 \\
\hline & & $\mathrm{GA}$ & 190 & $265 / 176 \cdot 9$ & 1.50 & & & \\
\hline & & $\mathrm{AA}$ & 44 & $81 / 38 \cdot 6$ & $2 \cdot 10$ & & & \\
\hline
\end{tabular}


Table 2. Continued

\begin{tabular}{|c|c|c|c|c|c|c|c|c|}
\hline Gene & SNP & Genotype & $n$ & $\begin{array}{c}\text { No. of URI per } \\
\text { person-year of follow-up }\end{array}$ & Rate & $\begin{array}{l}\text { Adjusted incidence } \\
\text { rate ratio per additional } \\
\text { minor allele* }\end{array}$ & $95 \% \mathrm{Cl}$ & $P_{\text {for trend }}$ \\
\hline & rs9409929 & GG & 327 & $524 / 298 \cdot 1$ & 1.76 & 1.01 & $0.89,1 \cdot 16$ & 0.85 \\
\hline & & $A G$ & 319 & $502 / 300 \cdot 7$ & 1.67 & & & \\
\hline & & AA & 69 & $117 / 63 \cdot 7$ & 1.84 & & & \\
\hline \multirow[t]{30}{*}{$V D R$} & rs4334089 & GG & 361 & $528 / 334.4$ & 1.58 & 1.15 & $1.01,1.31$ & $0.030 \ddagger$ \\
\hline & & $A G$ & 266 & $455 / 246 \cdot 1$ & 1.85 & & & \\
\hline & & AA & 88 & $152 / 84 \cdot 0$ & 1.81 & & & \\
\hline & rs10783219 & AA & 320 & $536 / 297 \cdot 8$ & 1.80 & 0.93 & $0.82,1.06$ & 0.26 \\
\hline & & AT & 298 & $447 / 277 \cdot 1$ & $1 \cdot 61$ & & & \\
\hline & & $\mathrm{TT}$ & 89 & $134 / 81 \cdot 8$ & 1.64 & & & \\
\hline & rs 4516035 & TT & 285 & $458 / 263.5$ & 1.74 & 0.91 & $0.80,1.04$ & $0 \cdot 19$ \\
\hline & & CT & 316 & $510 / 294.3$ & 1.73 & & & \\
\hline & & $\mathrm{CC}$ & 104 & $143 / 95 \cdot 2$ & 1.50 & & & \\
\hline & rs11568820 & $\mathrm{GG}$ & 409 & $589 / 376 \cdot 7$ & 1.56 & 1.23 & $1.07,1.40$ & $0.002 \ddagger$ \\
\hline & & GA & 217 & $373 / 204 \cdot 1$ & 1.83 & & & \\
\hline & & AA & 83 & $163 / 76 \cdot 0$ & $2 \cdot 14$ & & & \\
\hline & rs2238136 & $\mathrm{CC}$ & 409 & $689 / 382 \cdot 0$ & 1.80 & 0.93 & $0.81,1 \cdot 0$ & 0.32 \\
\hline & & CT & 258 & $367 / 237 \cdot 1$ & 1.55 & & & \\
\hline & & TT & 48 & $82 / 45 \cdot 0$ & 1.82 & & & \\
\hline & rs 1544410 & $\mathrm{CC}$ & 254 & $361 / 230 \cdot 5$ & 1.57 & $1 \cdot 10$ & $0.97,1.24$ & $0 \cdot 15$ \\
\hline & & CT & 340 & $548 / 317 \cdot 3$ & 1.73 & & & \\
\hline & & $\mathrm{TT}$ & 114 & $206 / 108 \cdot 3$ & 1.90 & & & \\
\hline & rs2228570 & GG & 302 & $459 / 282 \cdot 1$ & 1.63 & 1.07 & $0.94,1.21$ & 0.34 \\
\hline & & $A G$ & 318 & $517 / 295 \cdot 3$ & 1.75 & & & \\
\hline & & AA & 96 & $152 / 87 \cdot 0$ & 1.75 & & & \\
\hline & rs2853559 & $\mathrm{GG}$ & 280 & $455 / 262 \cdot 6$ & 1.73 & 0.94 & $0.82,1.07$ & 0.34 \\
\hline & & $A G$ & 334 & $524 / 306 \cdot 3$ & 1.71 & & & \\
\hline & & AA & 102 & $153 / 94.9$ & $1 \cdot 61$ & & & \\
\hline & rs7975232 & AA & 211 & $344 / 198 \cdot 3$ & 1.73 & 0.95 & $0.84,1.08$ & 0.43 \\
\hline & & $A C$ & 349 & $566 / 323 \cdot 2$ & 1.75 & & & \\
\hline & & $\mathrm{CC}$ & 141 & $194 / 128 \cdot 4$ & 1.51 & & & \\
\hline & rs7970314 & AA & 394 & $584 / 361 \cdot 7$ & 1.61 & $1 \cdot 17$ & $1.02,1.34$ & $0.018 \ddagger$ \\
\hline & & $A G$ & 230 & $390 / 218 \cdot 0$ & 1.79 & & & \\
\hline & & GG & 96 & $174 / 87 \cdot 9$ & 1.98 & & & \\
\hline
\end{tabular}

URI, upper respiratory infection; CUBN, cubilin; CYP-, cytochrome P450 enzyme; DBP, vitamin D binding protein; DHCR7, 7-dehydrocholesterol reductase enzyme; LRP2, low density lipoprotein-related protein 2 (also known as megalin); $R X R A$, retinoid-X receptor-A; $V D R$, vitamin $\mathrm{D}$ receptor; COPD, chronic obstructive pulmonary disease.

${ }^{*}$ Adjusted for age, sex, ethnicity, smoking history, influenza vaccination history, allocation to vitamin $\mathrm{D} v$. placebo, respiratory comorbidity (asthma $v$. COPD $v$. none).

† URI rate could not be calculated due to zero participants with the genotype or zero URI events.

$\ddagger$ Significant after correction for multiple comparisons testing, using the Benjamini and Hochberg method with a false discovery rate of $10 \%$.

mediators in response to viral stimuli might, therefore, be expected to increased susceptibility to URI. However, the fact that genotypic differences in host response to viral stimuli did not remain statistically significant after correction for multiple comparisons testing indicates that these may have arisen due to type 1 error, and our immunological findings should not, therefore, be given undue weight.

Our study has several strengths. To our knowledge, it represents the most comprehensive investigation into the influence of genetic variation in the vitamin $\mathrm{D}$ pathway on susceptibility to any infectious disease that has been conducted to date, in terms of the number of vitamin $\mathrm{D}$ pathway genes investigated. Any attendant potential for type 1 error in genetic analyses was minimised by stringent adjustment for multiple comparisons. We handled the potential for confounding by adjusting for potential confounders, and by conducting appropriate sensitivity analyses. We utilised a PCR-validated definition of URI, and captured events prospectively using a detailed symptom diary over a 1-year period. Our study population incorporated a broad range of participants, with a wide range of circulating $25(\mathrm{OH}) \mathrm{D}$ concentrations, with and without
Table 3. Genetic determinants of upper respiratory infection risk, validation cohort

\begin{tabular}{llccrc}
\hline Gene & SNP & Genotype & $\begin{array}{c}\text { Proportion } \\
\text { with } \geq 1 \text { URI }\end{array}$ & $\%$ & $P_{\text {for trend }}$ \\
\hline CYP3A4 & rs2740574 & AA & $48 / 691$ & 6.9 & 0.63 \\
& & AG & $2 / 45$ & 4.4 & \\
VDR & rs4334089 & GG & $0 / 1$ & 0.0 & \\
& & GG & $21 / 403$ & $5 \cdot 2$ & 0.048 \\
& & AG & $23 / 278$ & 8.3 & \\
& rs11568820 & GA & $6 / 56$ & 10.7 & \\
& & GG & $27 / 458$ & 5.9 & 0.19 \\
& & GA & $19 / 238$ & 8.0 & \\
& rs7970314 & AA & $4 / 41$ & 9.8 & \\
& & AG & $26 / 437$ & 5.9 & 0.26 \\
& & GG & $20 / 256$ & 7.8 & \\
& & GG & $4 / 44$ & 9.1 & \\
\hline
\end{tabular}

URI, upper respiratory infection; CYP-, cytochrome p450 enzyme; VDR, vitamin D receptor.

respiratory comorbidity, which enhances generalisability of our findings. The fact that we were able to replicate the association between rs4334089 genotype and susceptibility to URI in 
(a)

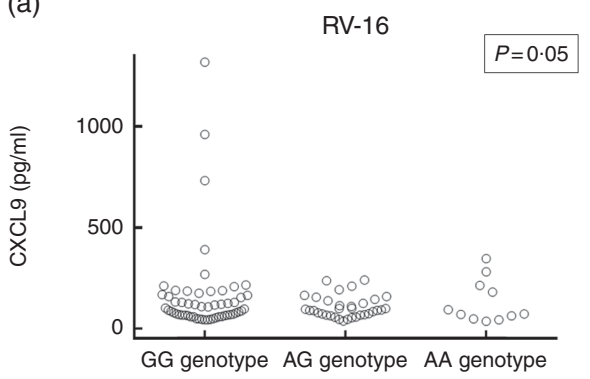

(c)

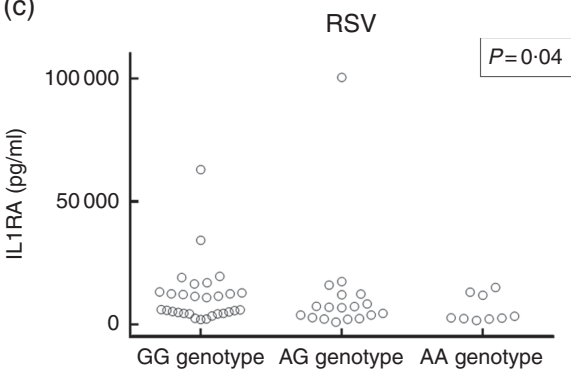

(e)

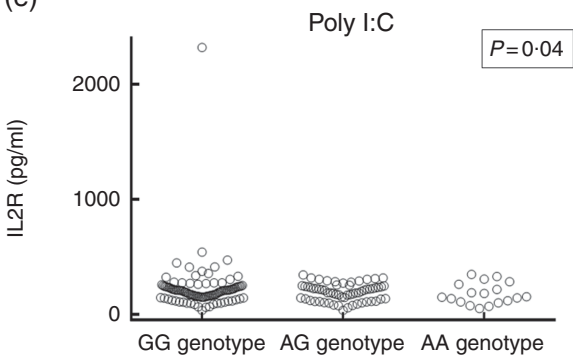

(b)

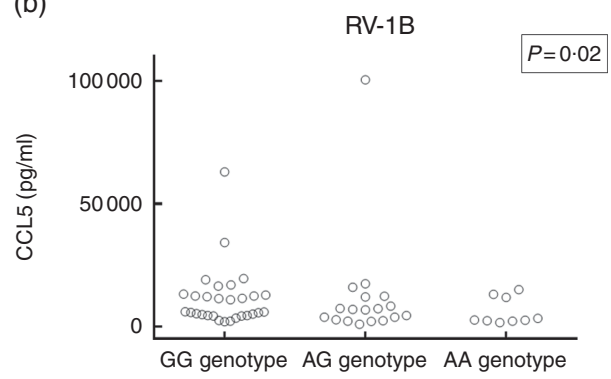

(d)

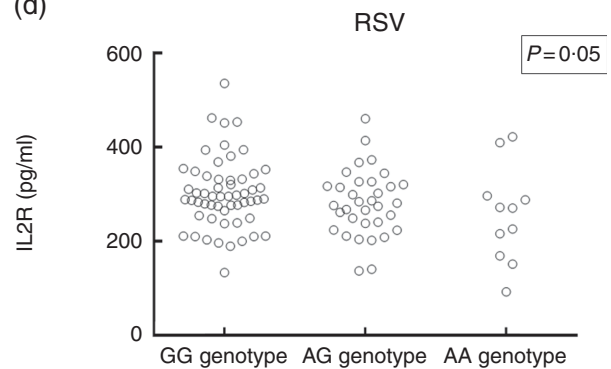

(f)

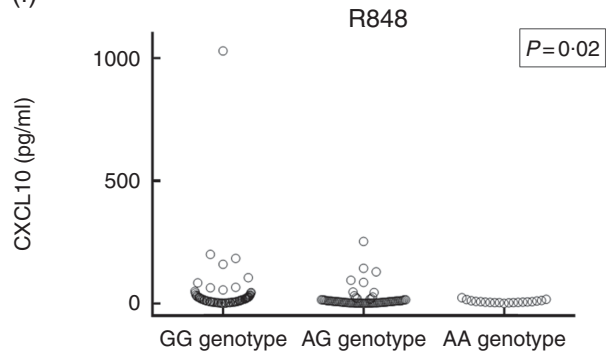

Fig. 2. Concentrations of virus-stimulated immune mediators by rs 4334089 genotype. (a) Rhinovirus (RV)-16-stimulated C-X-C motif ligand (CXCL)- 9 , whole blood supernatant (discovery cohort, $n$ 101); (b) RV-1B-stimulated C-C motif ligand (CCL)-5, whole blood supernatant (discovery cohort, $n$ 56); (c) respiratory syncytial virus (RSV)-stimulated IL-1RA, whole blood supernatant (discovery cohort, $n$ 101); (d) RSV-stimulated IL-2R, whole blood supernatant (discovery cohort, $n$ 101); (e) polyinosinic:polycytidylic acid (poly I:C)-stimulated IL-2R, whole blood supernatant (discovery cohort, $n$ 180); (f) resiquimod-stimulated CXCL10, peripheral blood mononuclear cell supernatant (validation cohort, $n$ 228). $P$ values are from regression analysis of log-transformed data; none was significant after correction for multiple comparisons testing, using the Benjamini and Hochberg method with a false discovery rate of $10 \%$.

diverse clinical cohorts (children $v$. adults), using a different case definition for URI (physician-diagnosed URI $v$. diarydefined URI), adds weight to this finding.

Our study also has some limitations. Our results are associative and descriptive; until a mechanism by which this VDR polymorphism influences susceptibility to URI is demonstrated, causal inferences should not be drawn. Our immunological studies investigated host responses in peripheral blood only; these may not reflect responses in the airway. Moreover, immunological data were only available for a sub-set of participants, and consequently the numbers of minor homozygotes contributing to analyses of inflammatory mediator concentrations were small: power to detect small differences in host response by genotype was, therefore, limited. It could be argued that our discovery and validation cohorts were too different in terms of age range to represent a true replication. However, the virology of URI in schoolchildren and adults in the UK is broadly comparable, in that RV are responsible for the majority of events in both populations ${ }^{(41,42)}$. Moreover, vitamin D supports broad-spectrum innate antiviral responses, which are effective against different respiratory viruses ${ }^{(7)}$. Our finding that genetic variation in VDR associates with susceptibility to URI in both children and adults is also consistent with findings from our recent individual participant data metaanalysis of randomised trials, which showed an overall protective effect of vitamin D supplementation against URI in participants aged 0-95 years, with strongest effects seen in those with the lowest $25(\mathrm{OH}) \mathrm{D}$ levels receiving daily or weekly vitamin D supplementation $^{(12)}$. In the validation cohort, it is likely that only a sub-set of URI were captured, since only relatively severe episodes of URI are likely to present to primary care. However, the fact that captured episodes were physiciandiagnosed provides extra confidence that diagnoses were accurate. Our study was also limited by the fact that we did not characterise viruses responsible for URI episodes; accordingly, we were unable to investigate whether VDR genotype influences susceptibility to URI in a pathogen-specific manner. Further research incorporating virological diagnosis could provide insight into this question; such studies may be challenging, as sensitivity of PCR for virus detection in URI can be $<50 \%$, particularly when 
sampling is delayed after onset of symptoms ${ }^{(43)}$. Finally, we draw attention to the fact that the vitamin D status of participants in our discovery cohort was relatively low $(20 \%<25 \mathrm{nmol} / 1,61 \%$ $<50 \mathrm{nmol} / \mathrm{l})$ : if the genetic associations reported are modified by circulating concentrations of $25(\mathrm{OH}) \mathrm{D}$, they may not be replicated in populations with higher vitamin D status.

In conclusion, we report that a polymorphism in VDR independently associates with susceptibility to URI in both adults and children. Given that the VDR is exclusively involved in vitamin D signalling, our findings lend weight to the growing body of evidence suggesting a role for the vitamin D pathway in mediating protection against respiratory infections.

\section{Acknowledgements}

The authors thank Dr Peter Timms, Ms Marion Rowe and Mr Tim Venton (Homerton Hospital, London) for performing 25(OH)D assays and Professor Seif Shaheen (Queen Mary University of London, UK) for his comments on this manuscript.

This is a summary of independent research funded by the National Institute for Health Research (NIHR) under its Programme Grants for Applied Research Programme (Ref. no. RP-PG-0407-10398). The views expressed are those of the authors and not necessarily those of the National Health Service (NHS), the NIHR or the Department of Health. The work was also supported by a Chair from Asthma UK (no. CH11SJ) and Medical Research Council Centre (grant no. G1000758). S. L. J. and R. T. W. are NIHR senior investigators. MAAS was supported by the Asthma UK grants no. 301 (1995-1998), no. 362 (1998-2001), no. 01/012 (2001-2004), no. 04/014 (2004-2007), the BMA James Trust, The Moulton Charitable Foundation (2004-current); age 11 years clinical follow-up is funded by the Medical Research Council (MRC) UK (G0601361) and age 18 years follow-up by the Biotechnology and Biological Sciences Research Council/MRC (MR/L012693/1).

A. C. reports personal fees from Novartis, Regeneron/Sanofi, ALK, Bayer ThermoFisher, GlaxoSmithKline and Boehringer Ingelheim, outside the submitted work. N. C. B. is a shareholder and employee of GlaxoSmithKline. S. L. J. reports personal fees from Therapeutic frontiers, Myelo Therapeutics $\mathrm{GmbH}$, Concert Pharmaceuticals, Bayer, Synairgen, Novartis, Boehringer Ingelheim, Chiesi, GlaxoSmithKline, Sanofi Pasteur, Centocor and Aviragen and holds patents for anti-virus therapies for respiratory diseases. A. R. M. reports grants from NIHR, during the conduct of the study. A. S. reports grants from medical research Council, JP Moulton Charitable Foundation and NIHR CRF, and personal fees from Thermo Fisher Scientific, during the conduct of the study.

A. R. M., D. A. J., C. J. G. and R. T. W. designed the discovery study. S. L. J., A. C., J. A. C. and A. S. designed the validation study. M. H., C. A. M., D. A. J. and J. A. C. developed and undertook genotyping assays. A. R. M., C. L. G. and D. A. J. developed and performed immunological assays in the discovery study. E. B. and A. G. T. developed and performed immunological assays in the validation study. D. A. J., J. A. C. and A. C. performed data analysis. A. R. M. and D. A. J. wrote the article; all other authors critically reviewed it and approved the final version.

The authors have no conflicts of interest to declare.

\section{Supplementary material}

For supplementary material/s referred to in this article, please visit https://doi.org/10.1017/S000711451800209X

\section{References}

1. Dasaraju PV \& Liu C (1996) Infections of the respiratory system. In Medical Microbiology, 4th ed. [S Baron, editor]. Galveston, TX: University of Texas Medical Branch at Galveston.

2. Fendrick AM, Monto AS, Nightengale B, et al. (2003) The economic burden of non-influenza-related viral respiratory tract infection in the United States. Arch Intern Med 163, 487-494.

3. Johnston SL (2005) Overview of virus-induced airway disease. Proc Am Thorac Soc 2, 150-156.

4. Gulliford MC, Dregan A, Moore MV, et al. (2014) Continued high rates of antibiotic prescribing to adults with respiratory tract infection: survey of 568 UK general practices. BMJ Open 4, e006245.

5. Brockman-Schneider RA, Pickles RJ \& Gern JE (2014) Effects of vitamin D on airway epithelial cell morphology and rhinovirus replication. PLOS ONE 9, e86755.

6. Hansdottir S, Monick MM, Lovan N, et al. (2010) Vitamin D decreases respiratory syncytial virus induction of NF-kappaBlinked chemokines and cytokines in airway epithelium while maintaining the antiviral state. J Immunol 184, 965-974.

7. Greiller CL \& Martineau AR (2015) Modulation of the immune response to respiratory viruses by vitamin D. Nutrients $\mathbf{7}$, $4240-4270$

8. Schogler A, Muster RJ, Kieninger E, et al. (2016) Vitamin D represses rhinovirus replication in cystic fibrosis cells by inducing LL-37. Eur Respir J 47, 520-530.

9. Telcian AG, Zdrenghea MT, Edwards MR, et al. (2017) Vitamin D increases the antiviral activity of bronchial epithelial cells in vitro. Antiviral Res 137, 93-101.

10. Jolliffe DA, Griffiths CJ \& Martineau AR (2013) Vitamin D in the prevention of acute respiratory infection: systematic review of clinical studies. J Steroid Biochem Mol Biol 136, 321-329.

11. Martineau AR, Cates CJ, Urashima M, et al. (2016) Vitamin D for the management of asthma. The Cochrane Database of Systematic Reviews 2016, issue 9, CD011511.

12. Martineau AR, Jolliffe DA, Hooper RL, et al. (2017) Vitamin D supplementation to prevent acute respiratory tract infections: systematic review and meta-analysis of individual participant data. BMJ 356, i6583.

13. Jolliffe DA, Greenberg L, Hooper RL, et al. (2017) Vitamin D supplementation to prevent asthma exacerbations: a systematic review and meta-analysis of individual participant data. Lancet Respir Med 5, 881-890.

14. van Etten E, Verlinden L, Giulietti A, et al. (2007) The vitamin $\mathrm{D}$ receptor gene FokI polymorphism: functional impact on the immune system. Eur J Immunol 37, 395-405.

15. Janssen R, Bont L, Siezen CL, et al. (2007) Genetic susceptibility to respiratory syncytial virus bronchiolitis is predominantly associated with innate immune genes. J Infect Dis 196, 826-834.

16. Kresfelder TL, Janssen R, Bont L, et al. (2011) Confirmation of an association between single nucleotide polymorphisms in the VDR gene with respiratory syncytial virus related disease in South African children. J Med Virol 83, 1834-1840.

17. Roth DE, Jones AB, Prosser C, et al. (2008) Vitamin D receptor polymorphisms and the risk of acute lower respiratory tract infection in early childhood. J Infect Dis 197, 676-680.

18. Han WG, Hodemaekers HM, Nagarajah B, et al. (2016) Association of vitamin D receptor polymorphism with susceptibility to symptomatic pertussis. PLOS ONE 11, e0149576. 
19. Martineau AR, MacLaughlin BD, Hooper RL, et al. (2015) Double-blind randomised placebo-controlled trial of bolusdose vitamin $\mathrm{D}_{3}$ supplementation in adults with asthma (ViDiAs). Thorax 70, 451-457.

20. Martineau AR, James WY, Hooper RL, et al. (2015) Vitamin $\mathrm{D}_{3}$ supplementation in patients with chronic obstructive pulmonary disease (ViDiCO): a multicentre, double-blind, randomised controlled trial. Lancet Respir Med 3, 120-130.

21. Martineau AR, Hanifa Y, Witt KD, et al. (2015) Double-blind randomised controlled trial of vitamin $\mathrm{D}_{3}$ supplementation for the prevention of acute respiratory infection in older adults and their carers (ViDiFlu). Thorax 70, 953-960.

22. Custovic A, Simpson BM, Murray CS, et al. (2002) The National Asthma Campaign Manchester Asthma and Allergy Study. Pediatr Allergy Immunol 13, Suppl. 15, 32-37.

23. Belgrave DC, Simpson A, Semic-Jusufagic A, et al. (2013) Joint modeling of parentally reported and physician-confirmed wheeze identifies children with persistent troublesome wheezing. J Allergy Clin Immunol 132, 575-583.e12.

24. Semic-Jusufagic A, Belgrave D, Pickles A, et al. (2014) Assessing the association of early life antibiotic prescription with asthma exacerbations, impaired antiviral immunity, and genetic variants in 17q21: a population-based birth cohort study. Lancet Respir Med 2, 621-630.

25. Jolliffe DA, Walton RT, Griffiths CJ, et al. (2016) Single nucleotide polymorphisms in the vitamin $\mathrm{D}$ pathway associating with circulating concentrations of vitamin D metabolites and non-skeletal health outcomes: review of genetic association studies. J Steroid Biochem Mol Biol 164, $18-29$.

26. Jolliffe DA, James WY, Hooper RL, et al. (2017) Prevalence, determinants and clinical correlates of vitamin D deficiency in patients with chronic obstructive pulmonary disease in London, UK. J Steroid Biochem Mol Biol 175, 138-145.

27. Paternoster L, Standl M, Waage J, et al. (2015) Multi-ancestry genome-wide association study of 21,000 cases and 95,000 controls identifies new risk loci for atopic dermatitis. Nat Genet 47, 1449-1456.

28. Zheng HF, Rong JJ, Liu M, et al. (2015) Performance of genotype imputation for low frequency and rare variants from the 1000 genomes. PLOS ONE 10, e0116487.

29. Jolliffe DA, Walton RT, Griffiths CJ, et al. (2015) Single nucleotide polymorphisms in the vitamin D pathway associating with circulating concentrations of vitamin D metabolites and non-skeletal health outcomes: review of genetic association studies. J Steroid Biochem Mol Biol 164, 18-29.
30. Butler MW, Burt A, Edwards TL, et al. (2011) Vitamin D receptor gene as a candidate gene for Parkinson disease. Ann Hum Genet 75, 201-210.

31. Ganmaa D, Munkhzul B, Fawzi W, et al. (2017) High-dose vitamin $\mathrm{D}_{3}$ during tuberculosis treatment in Mongolia. a randomized controlled trial. Am J Respir Crit Care Med 196, 628-637.

32. Sadeghi K, Wessner B, Laggner U, et al. (2006) Vitamin $\mathrm{D}_{3}$ down-regulates monocyte TLR expression and triggers hyporesponsiveness to pathogen-associated molecular patterns. Eur J Immunol 36, 361-370.

33. Do JE, Kwon SY, Park S, et al. (2008) Effects of vitamin D on expression of Toll-like receptors of monocytes from patients with Behcet's disease. Rheumatology (Oxford) 47, 840-848.

34. Hansdottir S, Monick MM, Lovan N, et al. (2010) Vitamin D decreases RSV induction of NF-kB-linked chemokines and cytokines in airway epithelium while maintaining the antiviral state. J Immunol 184, 965-974.

35. Yoon HJ, Zhu Z, Gwaltney JM Jr, et al. (1999) Rhinovirus regulation of IL-1 receptor antagonist in vivo and in vitro: a potential mechanism of symptom resolution. J Immunol 162, 7461-7469.

36. Hudock KM, Liu Y, Mei J, et al. (2012) Delayed resolution of lung inflammation in Il-1rn-/ - mice reflects elevated IL-17A/ granulocyte colony-stimulating factor expression. Am J Respir Cell Mol Biol 47, 436-444.

37. Elliott MB, Tebbey PW, Pryharski KS, et al. (2004) Inhibition of respiratory syncytial virus infection with the CC chemokine RANTES (CCL5). J Med Virol 73, 300-308.

38. Culley FJ, Pennycook AM, Tregoning JS, et al. (2006) Role of CCL5 (RANTES) in viral lung disease. J Virol 80, 8151-8157.

39. Short KR, Kroeze EJ, Fouchier RA, et al. (2014) Pathogenesis of influenza-induced acute respiratory distress syndrome. Lancet Infect Dis 14, 57-69.

40. Lindell DM, Lane TE \& Lukacs NW (2008) CXCL10/CXCR3mediated responses promote immunity to respiratory syncytial virus infection by augmenting dendritic cell and CD8(+) T cell efficacy. Eur J Immunol 38, 2168-2179.

41. Nicholson KG, Kent J, Hammersley V, et al. (1997) Acute viral infections of upper respiratory tract in elderly people living in the community: comparative, prospective, population based study of disease burden. BMJ 315, 1060-1064.

42. Horn ME, Brain EA, Gregg I, et al. (1979) Respiratory viral infection and wheezy bronchitis in childhood. Thorax 34, 23-28.

43. Jiang L, Lee VJ, Cui L, et al. (2017) Detection of viral respiratory pathogens in mild and severe acute respiratory infections in Singapore. Sci Rep 7, 42963. 